\title{
Analysis of the Indicators Achieved by the PhD Students Enrolled in Sectoral Operational Programme Human Resources Development (SOP HRD) Projects Implemented in the Universities of Agricultural Sciences and Veterinary Medicine from Romania
}

\author{
Vasile Lucian NAȘ, Sebastian Călin VAC, Sorina DÎRJAN, Alexandra Elena ANASTASIU * \\ University of Agricultural Sciences and Veterinary Medicine from Cluj-Napoca, Romania, 3-5 Calea \\ Mănăștur, 400372 Cluj-Napoca, Romania \\ *corresponding author, e-mail:: alexandra.anastasiu@usamvcluj.ro
}

Bulletin UASVM series Agriculture 73(1) / 2016

Print ISSN 1843-5254, Electronic ISSN 1843-5394

DOI 10.15835/buasvmcn-agr: 12013

\begin{abstract}
Taking into account the importance of human capital and the Romanian strategy in this area, in the last decade, a Sectoral Operational Programme concerning Human Resources (SOP HRD) has been implemented. In this study, we emphasize the impact of SOP HRD on the rate of defended doctoral theses and publishing activity of doctoral students from the fields of agronomy and veterinary medicine. Research was carried out on four public Universities of Agricultural Sciences and Veterinary Medicine from: Bucharest, Cluj-Napoca, Iasi and Timisoara. Data were processed using STATISTICA v. 8.0 for Windows, software. Very strong multiple correlations are emphasized between result indicators with values from $\mathrm{R}=0.999$ for UASVM Bucharest, to $\mathrm{R}=0.961$ UASVM Timisoara. Principal Component Analysis and Cluster Analysis show that published papers have a great importance (99.50\%-99.40\%) for the number of doctoral theses defended within SOP HRD projects developed by the UASVMs from Bucharest, Cluj-Napoca, and Iasi, while the presentations given at conferences seem to have a minor role. In UASVM Timisoara's case, both published papers and presentations given at conferences appear to have almost the same importance (51.08\%, and $48.92 \%$, respectively) for the number of defended doctoral theses.
\end{abstract}

Keywords: Cluster Analysis, Multiple Regression, Principal Component Analysis,

\section{INTRODUCTION}

As part of the European Union, Romania needs to adopt strategic options, which makes it align with the Lisbon Strategy and the overall European Union policies. A first step in meeting this desideratum was the elaboration of the Strategic Reference Framework 2007-2013 (NSRF). A series of interventions in several structural areas were undertaken. Among these, human capital is of first importance, aiming to develop strategies and measures at national level, focused on diminishing and even excluding, if possible, the inequality of opportunities among vulnerable groups such as disabled people, Roma, or even women.

A useful tool in achieving the above mentioned aim, in the field of human resources, is the Sectoral Operational Programme Human Resources Development (SOP HRD). It was structured on seven priority axes. The main objectives of this programme were to contribute to the improvement 
of the school response to labor market exigencies, as well as promoting highly qualified work forces in all domains required by national economy. Within Priority Axis 1 - Education and training in support of growth and development of a knowledge based society (ESF), an important role is granted to the Major Intervention Domain 1.5. "Doctoral and Post-doctoral Programmes in Support of Research". During 2007-2013 a number of 8,195 individuals were included in this programme (SOP HRD 20072013, Annual Report of Implementation, 2008, 2009, 2010, 2011, 2012, 2013, 2014).

This study aims to emphasize the impact of SOP HRD on the doctoral theses defending rate, and publishing activity of doctoral students from the fields of agronomy and veterinary medicine, simultaneously with emphasizing the strength of the relationship between the publishing activity, participations to conferences and rate of defended theses.

\section{MATERIAL AND METHOD}

Research was carried out on four state Universities of Agricultural Sciences and Veterinary Medicine (UASVM) from: Bucharest, Cluj-Napoca, Iasi and Timisoara.

Data were collected from public reports available from 8 SOP HRD projects, 2 by each university. The output of the monitoring of the results indicators, took into consideration within present study, are presented in Table 1.

The results take into consideration the average of the indicators collected from both projects by each university.

In order to emphasize the interrelation between published papers, presentations at conferences, and rate of defended theses we use a multiple correlations algorithm. Cluster analysis (CA) was used in order to group three indicators (number of defended theses, number of published papers, number of presentations given at conferences) function of their inter-relationships.

The Factorial Analysis - Principal Component Analysis (PCA), respectively aims to classify the importance of the number of defended theses, and number of $\mathrm{PhD}$ students (target group), function of two main factors, the number of published papers (Factor 1) and number of presentations given at conferences (Factor 2) from the target group, respectively. Data were processed with STATISTICA v. 8.0 for Windows, software.

\section{RESULTS AND DISCUSSION}

The multiple correlation analysis applied to the result indicators reported by UASVM Bucharest within the concerned projects emphasizes a very strong interdependence between the considered items, demonstrated by the value of the multiple correlation coefficient $\mathrm{R}=0.999$, which explained 99.90\% of the sample (Fig. 1).

The PCA (Fig. 2a) demonstrates that Factor 1 (number of published papers) has a major importance $(91.36 \%)$ upon number of defended theses, while Factor 2 (number of presentations given at conferences) has a minor importance (8.64\%). The importance of Factor 2 is larger for the number of doctoral students from the target group.

The cluster analysis groups the number of defended doctoral thesis and presentations held at conferences in the same cluster, while published papers constitute a single cluster (Fig. 2b). These results emphasize the important publishing activity of doctoral students, but also the

Tab. 1. The results indicators reported by each analyzed SOP HRD project

\begin{tabular}{|c|c|c|c|c|c|}
\hline \multirow{2}{*}{$\begin{array}{c}\text { Indicator } \\
\text { UASVM }\end{array}$} & \multirow{2}{*}{ Project } & \multirow{2}{*}{$\begin{array}{c}\text { Target } \\
\text { group (no.) }\end{array}$} & \multicolumn{3}{|c|}{$\%$ of fulfillment } \\
\hline & & & Defended theses & Presented papers & Published papers \\
\hline \multirow[t]{2}{*}{ Bucharest } & $107 / 1.5 / S / 76888$ & 74 & 97.30 & 262.14 & 137.84 \\
\hline & $88 / 1.5 / \mathrm{S} / 52614$ & 29 & 100 & 201.66 & 386.66 \\
\hline \multirow[t]{2}{*}{ Cluj-Napoca } & $6 / 1.5 / S / 20$ & 50 & 98 & 18 & 256 \\
\hline & $88 / 1.5 / S / 49598$ & 50 & 100 & 34 & 345.33 \\
\hline \multirow[t]{2}{*}{ Iasi } & 6/1.5/S/7-ID4781 & 30 & 96.66 & 253.33 & 230 \\
\hline & $88 / 6 / 1.5 / \mathrm{S} / 52176$ & 50 & 100 & 337 & 286 \\
\hline \multirow[t]{2}{*}{ Timisoara } & 6/1.5/S/21-ID6540 & 60 & 100 & 97.62 & 131.90 \\
\hline & $88 / 6 / 1.5 / \mathrm{S} / 80127$ & 60 & 100 & 159.44 & 158.18 \\
\hline
\end{tabular}


importance of this activity for doctoral students in preparing their theses.

Concerning the indicators reported by UASVM Cluj-Napoca, there is also a very strong interdependence between the analyzed items. The multiple correlation coefficient $\mathrm{R}=0.996$ explains 99\% of the sample (Fig. 3).
Similarly, with results obtained in UASVM Bucharest, from PCA (Fig. 4a), in UASVM ClujNapoca, it results that Factor 1 number of published papers) has a major importance (91.34\%) upon the number of defended theses, while Factor 2 (number of presentations given at conferences) has a minor importance (8.66\%). The

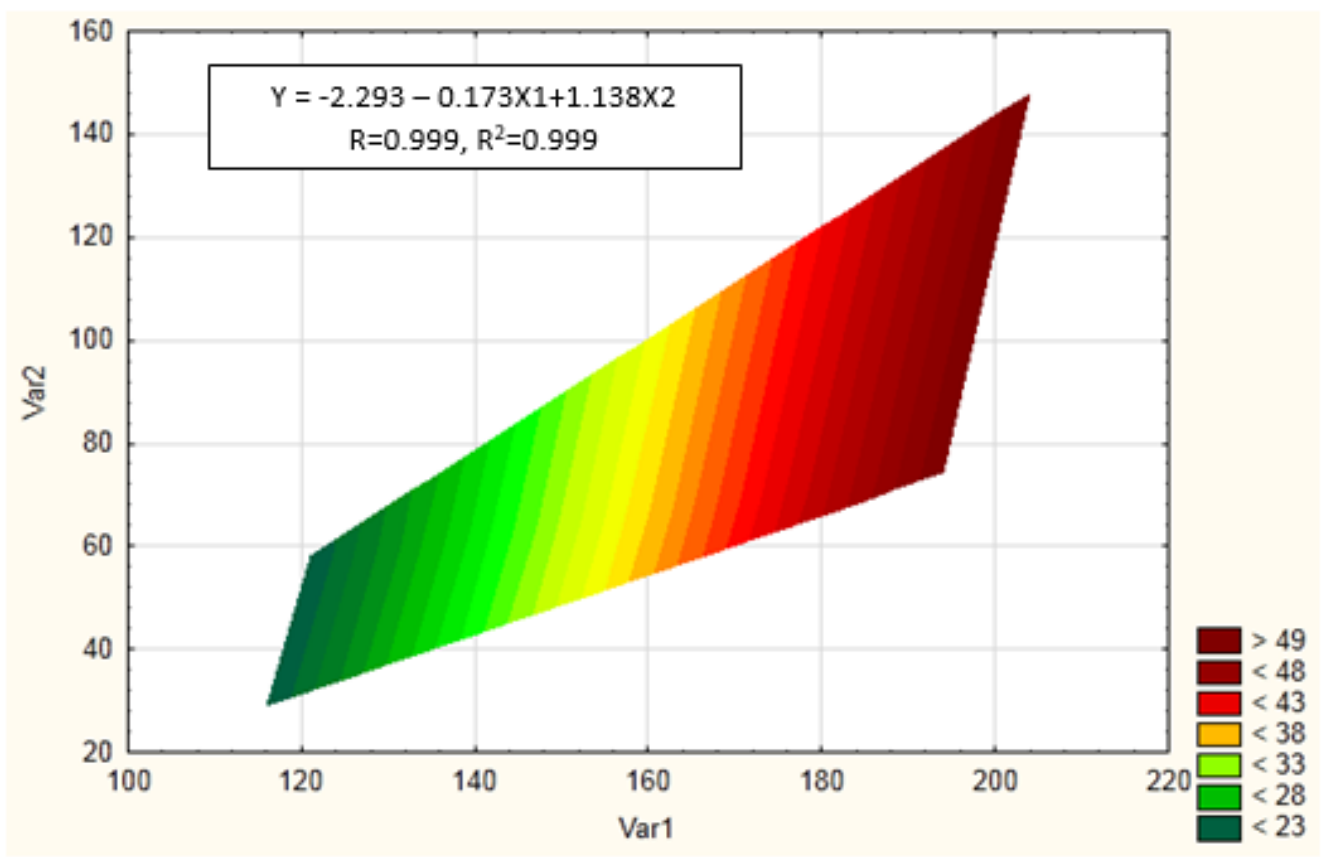

Note: $\operatorname{Var} 1, \mathrm{X} 1$ - presented papers; $\operatorname{Var} 2, \mathrm{X} 2$ - published papers.

Fig. 1. The interrelationship between presented papers, published papers and defended doctoral theses of the doctoral students from the University of Agricultural Sciences and Veterinary Medicine Bucharest, during 2012-2014.
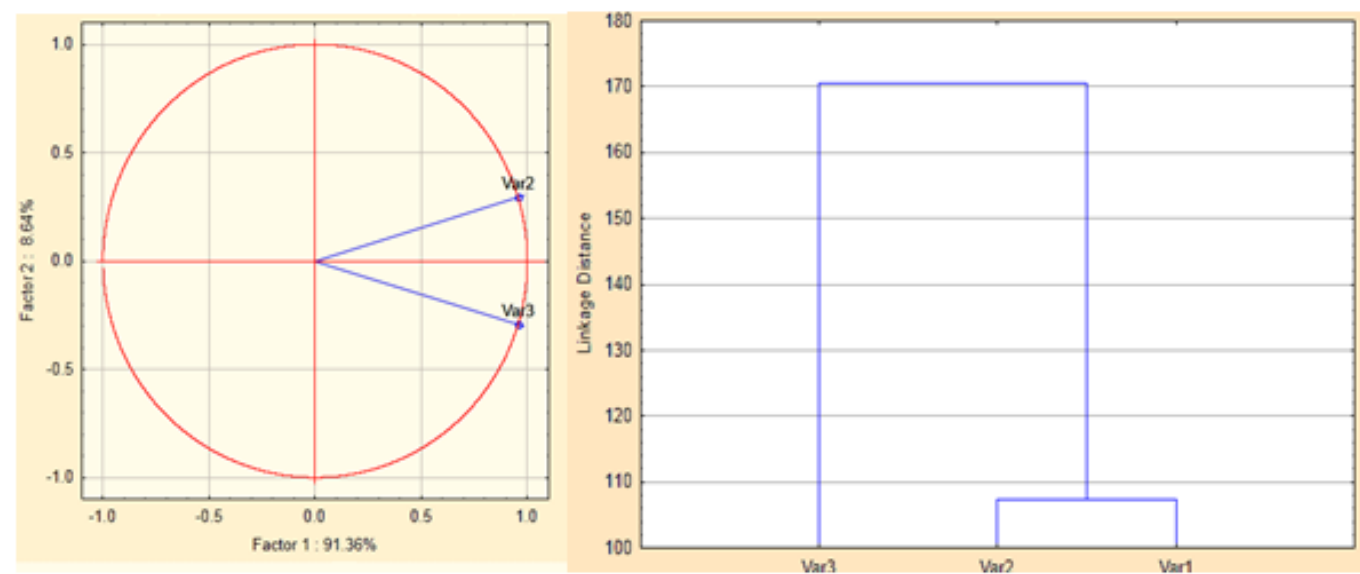

Note: $\operatorname{Var} 1$ - defended doctoral theses; Var 2 - presented papers; Var 2 - published papers.

a.PCA

b.CA

Fig. 2. The PCA and CA applied to the result indicators of the SOP HRD projects analyzed from the University of Agricultural Sciences and Veterinary Medicine Bucharest, during 2012-2014. 
importance of Factor 2 is bigger for the number of doctoral students from target group. The cluster analysis groups the number of defended doctoral theses and presentations given to conferences in the same cluster, while published papers constitute a single cluster (Fig. 4b).
These results emphasize the important publishing activity of doctoral students, but also the importance of this activity for doctoral students in preparation of their theses.

In UASVM Iasi, similarly, with results obtained in UASVM Bucharest and Cluj-Napoca, there is also

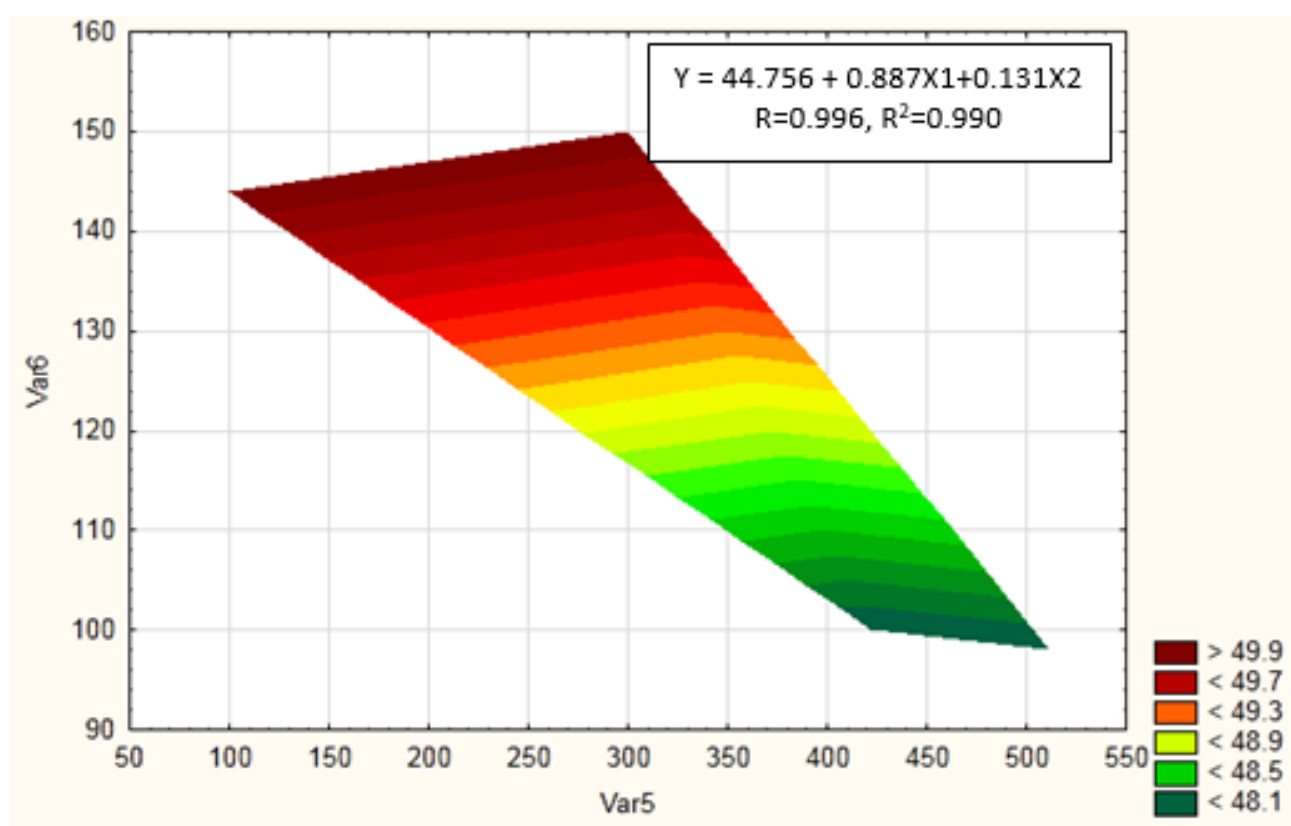

Note: Var 5, X1 - presented papers; Var 6, X2 - published papers.

Fig. 3. The interrelationship between presented papers, published papers and the defended doctoral theses within the University of Agricultural Sciences and Veterinary Medicine Cluj-Napoca, during 2012-2014.
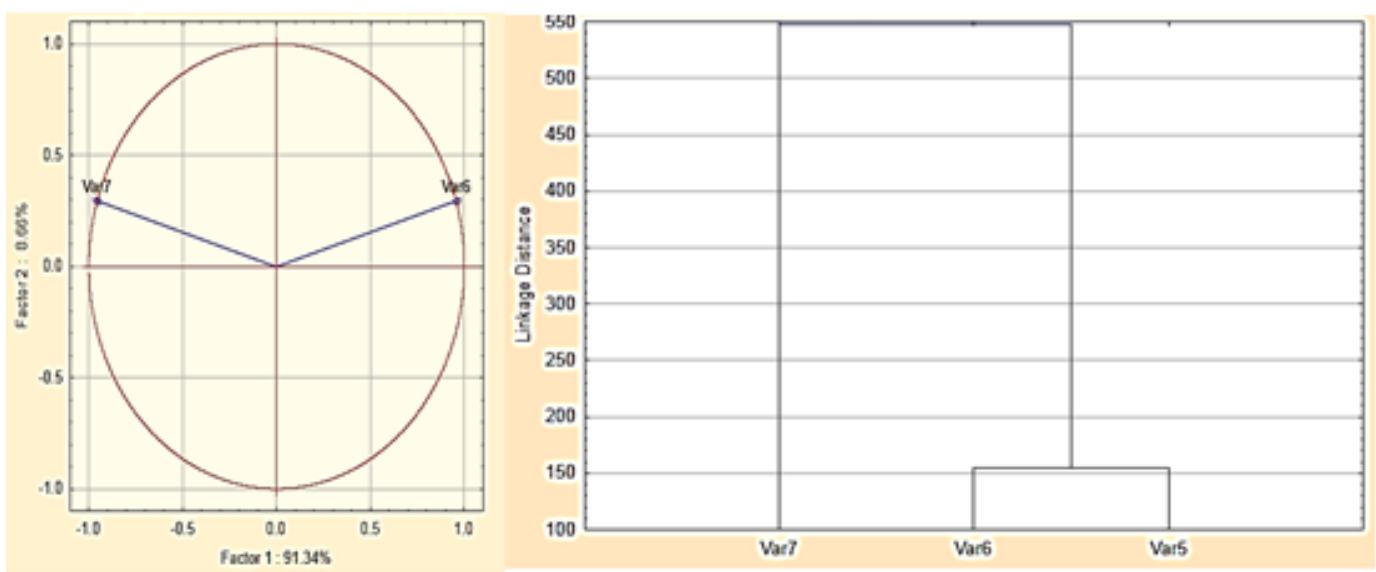

Note: Var 5 - defended doctoral theses; Var 6-presented papers; Var 7 - published papers.

a.PCA

b.CA

Fig. 4. The PCA and CA applied to the result indicators of the SOP HRD projects analyzed from the University of Agricultural Sciences and Veterinary Medicine Cluj-Napoca, during 2012-2014. 
a very strong interdependence between numbers of defended theses, number of published papers, and number of presentations given at conferences is reported. The multiple correlation coefficient $\mathrm{R}$ $=0.993$ explains $98.60 \%$ of the sample (Fig. 5).

In UASVM Iasi, the PCA (Fig. 6a) emphasize a particular situation. It results that Factor 1 (number of published papers) has a major importance (99.50\%) upon number of defended thesis, while contribution of the Factor 2 (number of presentations given at conferences) may be neglected $(0.50 \%)$. Thus, the importance of Factor 1 is much bigger compared with Factor 2, for both, the number of doctoral students from the target group and the number of defended doctoral theses (Fig. 6a).

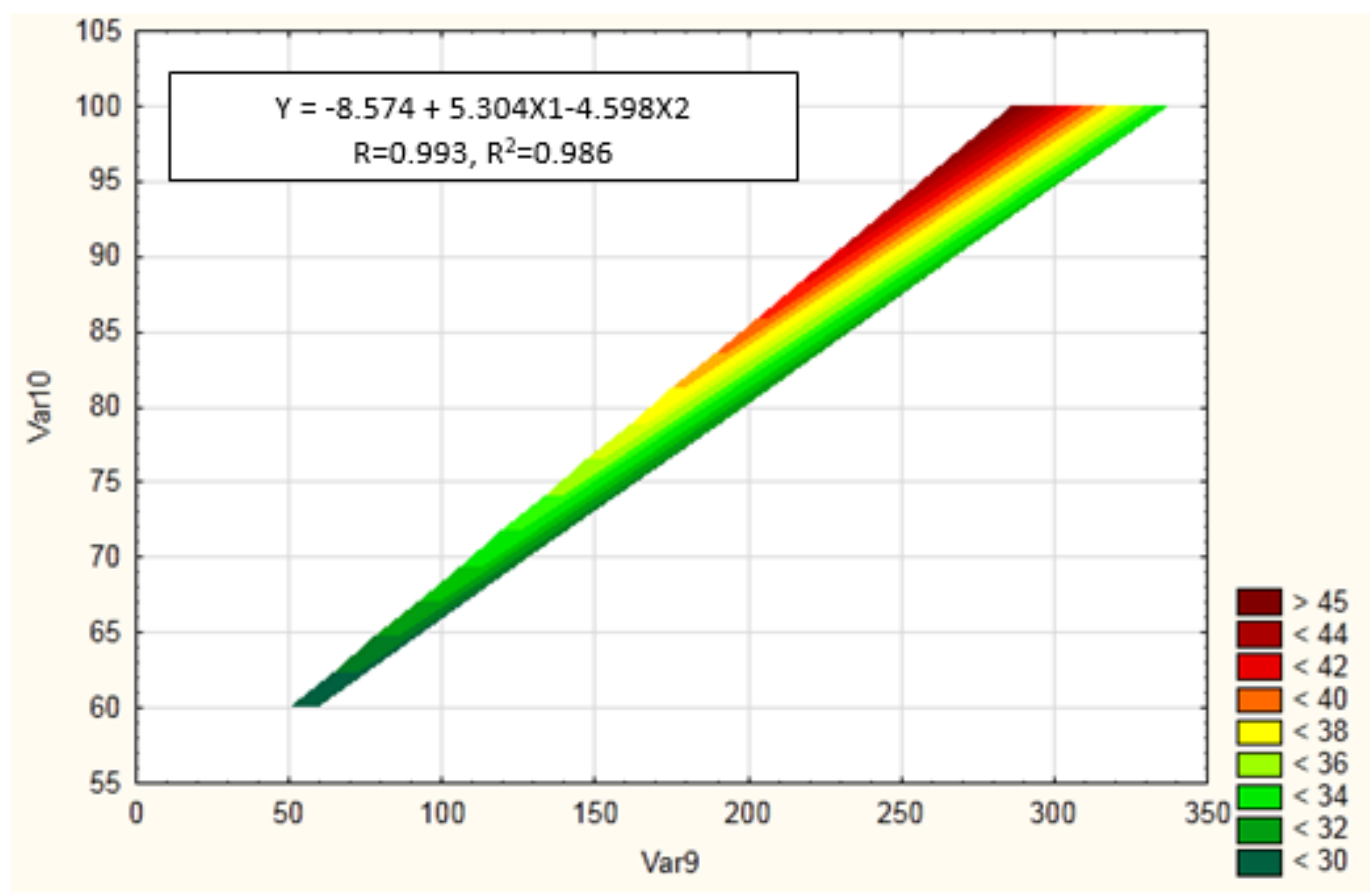

Note: Var 5, X1 - presented papers; $\operatorname{Var} 6, \mathrm{X} 2$ - published papers.

Fig. 5. The interrelationship between presented papers, published papers and from the defended doctoral theses within the University of Agricultural Sciences and Veterinary Medicine Iasi, during 2012-2014.
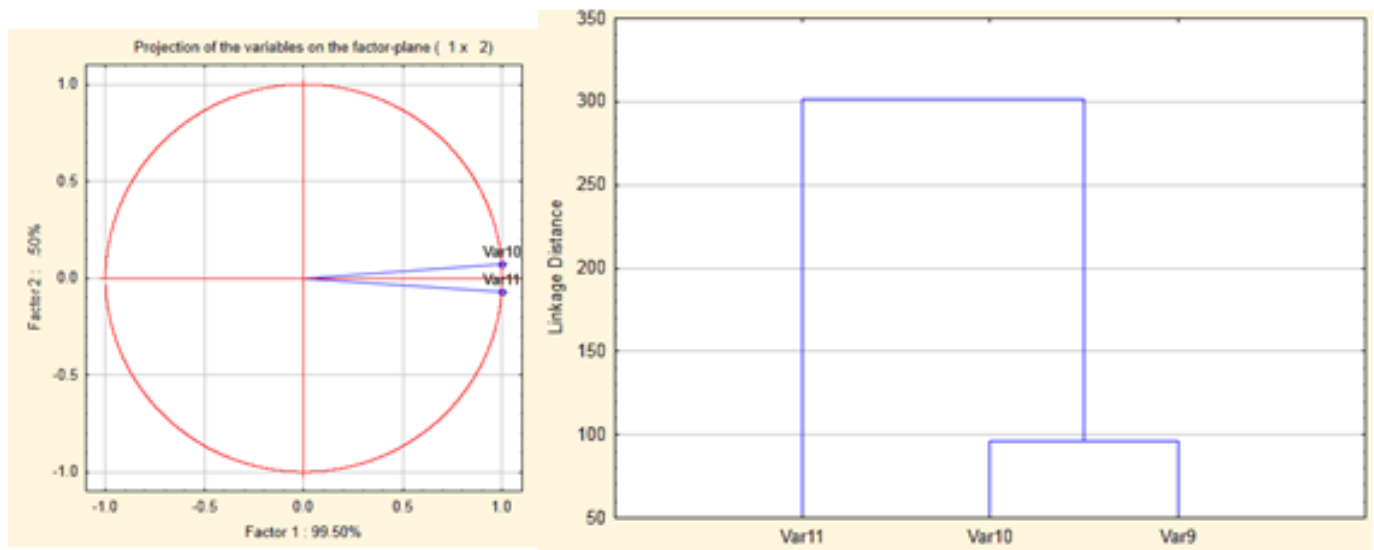

Note: $\operatorname{Var} 9$ - defended doctoral theses; $\operatorname{Var} 10$ - presented papers; $\operatorname{Var} 11$ - published papers.

a.PCA

b.CA

Fig. 6. The PCA and CA applied to the result indicators of the SOP HRD projects analyzed from the

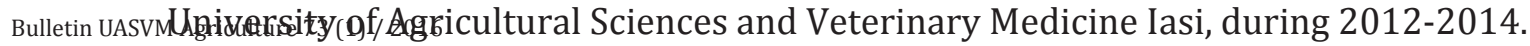


The cluster analysis groups the number of defended doctoral theses and presentations held at conferences in the same cluster, while published papers constitute a single cluster (Fig. 6b). Similarly with previous results reported for UASVM Bucharest, and UASVM Cluj-Napoca, these results emphasize the important publishing activity of doctoral students, but also the importance of this activity for doctoral students in preparation of their theses.

If we analyze the concerned item in UASVM Timisoara, we also note very strong interdependence between the analyzed result indicators. The multiple correlation coefficient $\mathrm{R}=0.961$ explains $92.40 \%$ of the sample (Fig. 7).

Apart from the results obtained in the other investigated UASVMs, Bucharest, Cluj-Napoca, and Iasi, respectively, the PCA (Fig. 8a) applied to the same indicators in UASVM Timisoara, highlights that Factor 1 (number of published papers), and Factor 2 (number of presentations held at conferences) have similar importance $(51.08 \%$, and $48.92 \%$, respectively).
If the 1st Factor has almost the same importance for both considered outputs, (defended doctoral theses and number of students from the target group, respectively), Factor 2 has much more influence on the number of students from the target group (Fig. 8.a). The cluster analysis also emphasizes different results compared to those reported.

Although CA emphasizes two groups, as reported for the other universities (Figs. $2 b, 4 b$, and $6 \mathrm{~b}$ ), in this case, presentations held atconferences and published papers belong to the same cluster, while defended doctoral theses constitute a single cluster (Fig. 8b).

These differences may be subject of the different approaches adopted by the doctoral school management of the analyzed universities, meaning that while UASVMs from Bucharest, ClujNapoca, and Iasi are much concerned to promote publishing activity in support of the elaboration of doctoral theses, the UASVM from Timisoara promotes, almost at the same extent, both publishing activity and conference presentations.

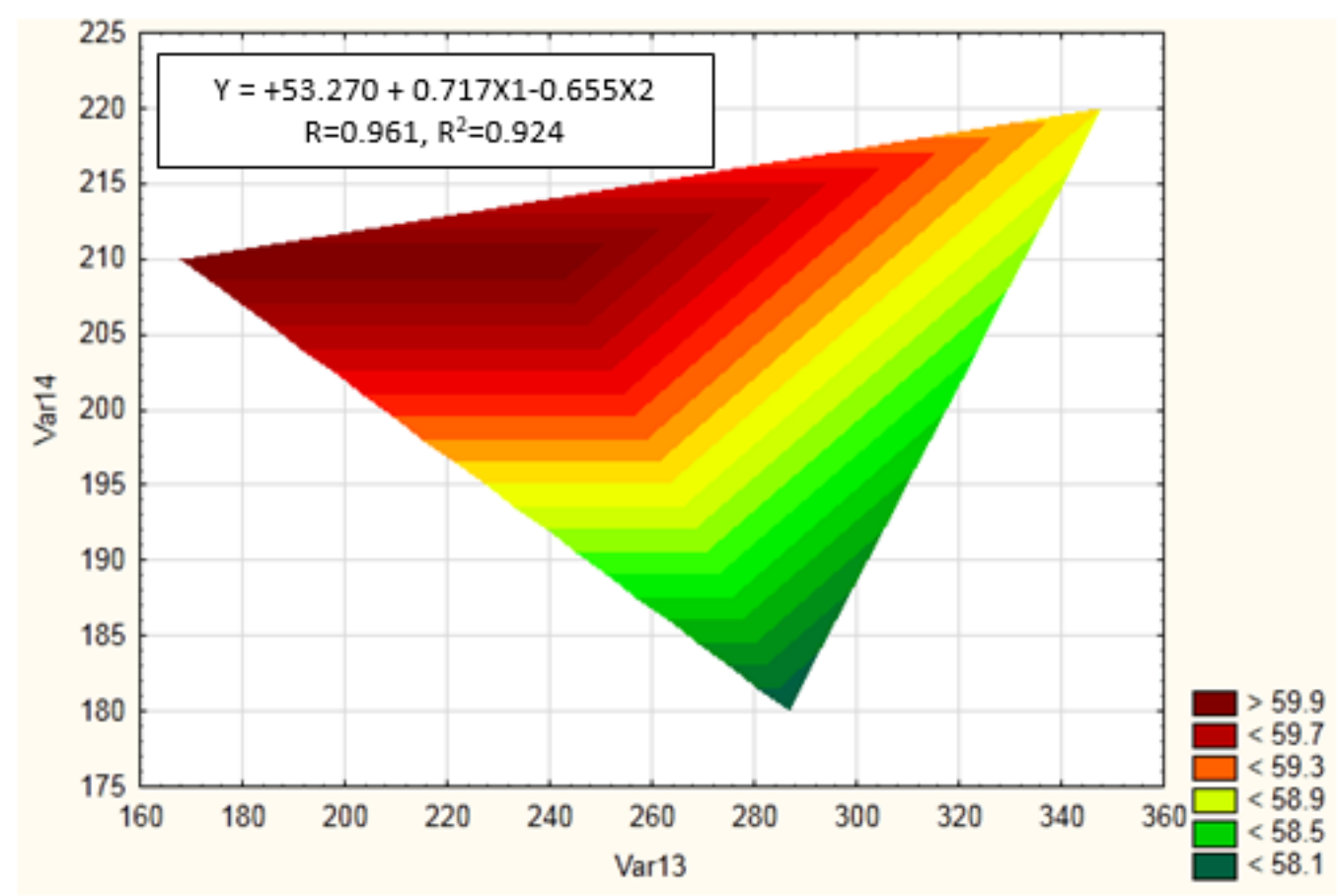

Note: $\operatorname{Var} 13, \mathrm{X} 1$ - presented papers; Var 14, X2 - published papers.

Fig. 7. The interrelationship between presented papers, published papers and the defended doctoral theses from the University of Agricultural Sciences and Veterinary Medicine Timisoara, during 2012-2014. 

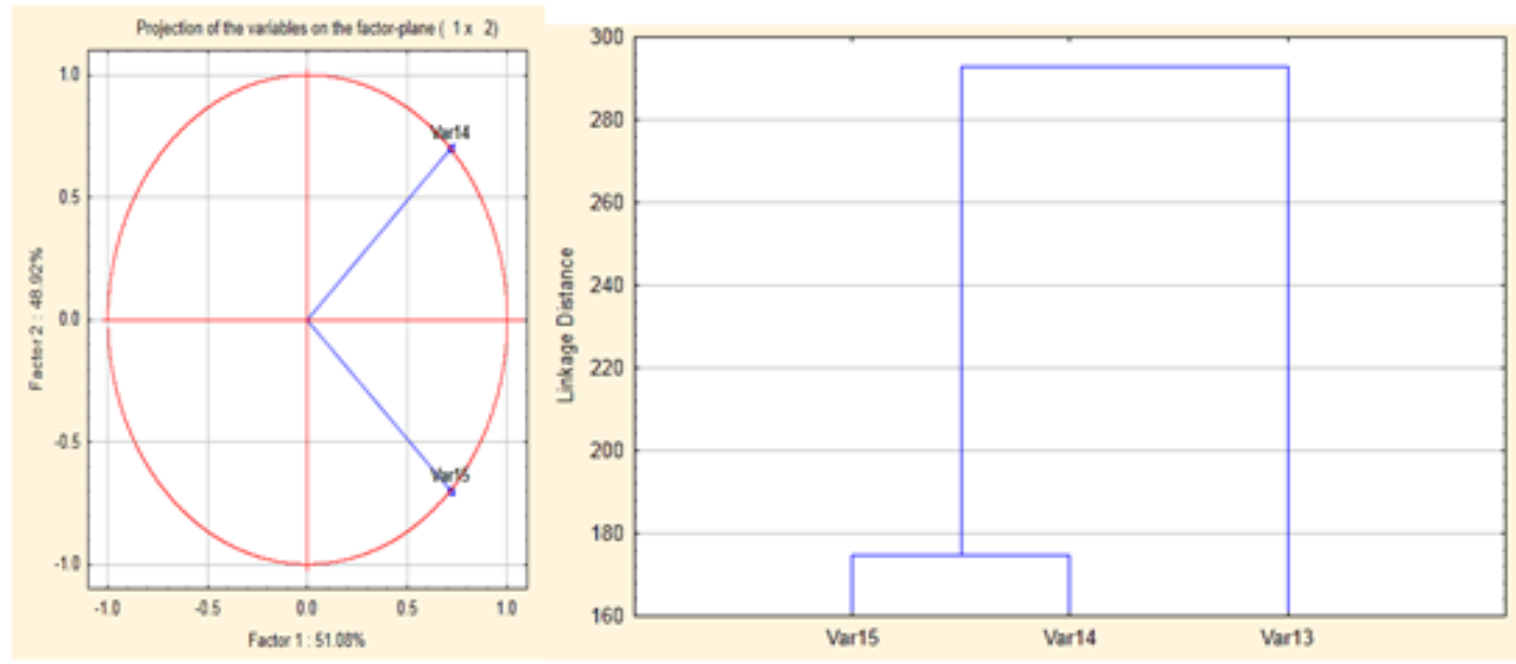

Note: Var 13 - defended doctoral theses; Var 14-presented papers; Var 15 - published papers.

a.PCA

b.CA

Fig. 8. The PCA and CA applied to the result indicators of the analyzed SOP HRD projects from the University of Agricultural Sciences and Veterinary Medicine Timisoara, during 2012-2014.

\section{CONCLUSION}

Very strong multiple correlations are emphasized between the result indicators reported by UASVMs from Bucharest, Cluj-Napoca, Iasi, and Timisoara. The strongest interdependence between the number of defended doctoral theses, number of published papers and number of presented papers is reported in UASVM Bucharest $\left(R=0.999, R^{2}=0.999\right)$, while for the UASVM Timisoara, even very strong multiple correlation is reported, it is lower $\left(\mathrm{R}=0.961, \mathrm{R}^{2}=0.924\right)$ compared to those noted for the other considered UASVMs.

According to the Principal Component Analysis, the role of the published papers have a great importance (99.50\%-99.40\%) for the number of defended doctoral theses within the SOP HRD projects, developed by the UASVMs from Bucharest, Cluj-Napoca, and Iasi, while the presentations given at conferences seem to have a minor role. Not the same situation is reported for UASVM Timisoara, where both published papers and presentations given at conferences appear to have almost the same importance $(51.08 \%$, and $48.92 \%$, respectively) for the number of defended doctoral theses. These results are also confirmed by the Cluster Analysis conducted within the same UASVMs.

Our study also shows the positive impact of the implementations of the SOP HRD projects upon doctoral programmes in the fields of Agronomy and Veterinary Medicine, expressed by the high rate of accomplishing the proposed value for the indicator consisting in defended doctoral theses, and overcoming with up to more than $300 \%$ of the values of the other two indicators, meaning number of published papers and number of presentations held at conferences, respectively.

\section{REFERENCES}

1. *** (2008). Romanian Government, Ministry of Labor, Family and equality of Chances, SOP HRD 2007-2013, Annual Report of Implementation [In Romanian].

2. *** (2009). Romanian Government, Ministry of Labor, Family and equality of Chances, SOP HRD 2007-2013, Annual Report of Implementation [In Romanian].

3. *** (2010). Romanian Government, Ministry of Labor, Family and equality of Chances, SOP HRD 2007-2013, Annual Report of Implementation [In Romanian]. 
4. *** (2011). Romanian Government, Ministry of Labor, Family and equality of Chances, SOP HRD 2007-2013, Annual Report of Implementation [In Romanian].

5. *** (2012). Romanian Government, Ministry of Labor, Family and equality of Chances, SOP HRD 2007-2013, Annual Report of Implementation [In Romanian].
6. *** (2013). Romanian Government, Ministry of Labor, Family and equality of Chances, SOP HRD 2007-2013, Annual Report of Implementation [In Romanian].

7. *** (2014). Romanian Government, Ministry of Labor, Family and equality of Chances, SOP HRD 2007-2013, Annual Report of Implementation [In Romanian]. 